\title{
Aprender com mobilidade: utilização das Tecnologias da Informação e Comunicação Móveis e Sem Fio como potencializadoras da interação em processos educativos
}

Claudio Cleverson de Lima, Universidade Feevale, e-mail: claudiolima@feevale.br Patrícia B. Scherer Bassani, Universidade Feevale, e-mail: patriciab@feevale.br Débora Nice Ferrari Barbosa, Universidade Feevale, e-mail: deboranice@feevale.br

Resumo. O acesso aos recursos da web 2.0 é cada vez mais realizado com o uso das TIMS (Tecnologias de Informação e Comunicação Móveis e Sem Fio). Este estudo teve como objetivo investigar como o potencial de interação e cooperação das ferramentas da web 2.0, acessadas por meio das TIMS, pode oportunizar a interação de alunos em exercício domiciliar com o contexto escolar. A metodologia envolveu um estudo de caso, com base em observação participante, diário de campo, entrevista e questionário. Resultados apontam que, apesar da necessidade de mais laboratórios de informática nas escolas, bem como suporte técnico e formação docente para utilização pedagógica das tecnologias digitais, as ferramentas da web 2.0, acessadas por meio das TIMS, oportunizam espaços de interação, cooperação e aprendizagem.

Palavras-chave: aprendizagem móvel, interação, cooperação, TIMS, ferramentas da web 2.0.

Abstract. The access to the resources of web 2.0 is increasingly performed with the use of TIMS (Technologies of Information and Communication Mobile and Wireless). This study investigated how the potential for interaction and cooperation of web 2.0 tools, accessed through TIMS, can provide the interaction of students in home exercise with the school context. The methodology involved a case study, based on participant observation, field diary, interview and questionnaire. Results show that, despite the need for more computer labs in schools as well as technical support and training teachers for pedagogical use of digital technologies, the web 2.0 tools, accessed through TIMS, provide spaces for interaction, cooperation and learning.

Keywords: mobile learning, interaction, cooperation, TIMS, web 2.0 tools.

\section{Introdução}

O termo web 2.0, surgido em 2004, nomeia a fase da internet marcada pela facilidade de interação e publicação de conteúdo online (O’REILLY, 2004). O escopo dinâmico de atuação desse novo formato conceitual da web permite níveis mais abrangentes de interação e cooperação entre os sujeitos, destacando-se a interatividade e a participação do usuário com a estrutura e o conteúdo da página. Ao invés de navegadores passivos, que apenas acessam o conteúdo, os usuários da web 2.0 fazem proposição de serviços, produzem e divulgam informações e participam ativamente do processo. Migra-se do modelo de comunicação tradicional, de um-para-muitos, para o modelo de comunicação interativa, de muitos-para-muitos (PRIMO, 2007). Assim, as ferramentas da web 2.0 apresentam como característica fundamental o foco na participação do sujeito, potencializando processos de colaboração e compartilhamento, e evidenciando possibilidades de utilização em processos educativos.

Considera-se que as ferramentas sociais da web 2.0 são artefatos culturais, na medida em que, interligando pessoas, e não tão-somente máquinas, são produtos de nossos próprios propósitos e ideias. A forma com que os sujeitos se apropriam dessas tecnologias reinventa constantemente suas características (AMARAL et al, 2008) e, vistas como artefatos culturais, as ferramentas da web 2.0 assumem um enfoque a partir da perspectiva de utilização pedagógica em processos de ensino e de aprendizagem. 
A linha teórica piagetiana, aqui adotada, defende que a aprendizagem decorre da interação entre o sujeito e o objeto do conhecimento. Também na aprendizagem mediada pelas tecnologias digitais, interação é elemento fundamental. Muitas ferramentas da web 2.0 oportunizam aos sujeitos o papel de autor/coautor e leitor, caracterizando a cooperação. Cooperar, sob a epistemologia piagetiana, significa “operar em comum”. Além disso, a cooperação é entendida como o mais alto nível de socialização (PIAGET, 1973).

Tendo como objeto as tecnologias digitais e com base nos estudos de Piaget, Primo (2007) analisa os diferentes modos de interação mediada pelo computador sob a ótica das ações/relações entre os envolvidos no processo. Primo (2007) distingue dois tipos de interação: reativa e mútua. A interação reativa é aquela cujas ações se estabelecem acerca de determinadas condições iniciais, atendendo a objetivos específicos, e cuja resposta será sempre prevista em razão de um determinado estímulo. Já a interação mútua é mais complexa do ponto de vista social, pois nela o resultado da mesma não pode ser previsto antecipadamente, sendo construído durante o processo interativo e se atualizando nas ações entre os sujeitos (PRIMO, 2000).

As tecnologias e ferramentas digitais foram adotadas rapidamente nas atividades educativas devido à sua capacidade de possibilitar a interação e a cooperação (PRIMO e SMANIOTTO, 2006; SACCOL et al., 2011). Entre as vantagens dessa adoção está a possibilidade de acesso a qualquer tempo e lugar, possibilitando ampliar o alcance da sala de aula. Assim, alunos impossibilitados de frequentar a escola, por questões de saúde ou outra, podem acessar o contexto escolar por meio das ferramentas da web 2.0. Portanto, a forma como o aluno vai acessar esse contexto converte-se em uma questão fundamental e, ao permitir o acesso remoto ao contexto escolar, as Tecnologias da Informação e Comunicação Móveis e Sem Fio (TIMS) possibilitam a mobilidade. Conjugadas com a web e suas diversas formas de conexão, as TIMS possibilitam a aprendizagem com mobilidade, entendida como a possibilidade de acesso interativo ao contexto escolar a qualquer tempo e lugar (SACCOL et al, 2011).

Entende-se como fundamental o papel que as ferramentas de comunicação interativas exercem nos processos pedagógicos mediados pelas tecnologias digitais. As características interativo-cooperativas presentes em algumas ferramentas da web 2.0 possibilitam a construção de processos de ensino e aprendizagem no ambiente virtual. Dessa forma, este estudo teve como objetivo investigar o potencial de utilização das TIMS para o acesso às ferramentas da web 2.0, oportunizando processos interativocooperativos e a construção do conhecimento. O presente artigo apresenta o contexto e a questão de pesquisa na seção 2; na seção 3 apresentam-se os materiais, métodos e a aplicação da proposta; na seção 4, os resultados e a discussão, e na seção 5 as considerações finais.

\section{Contexto e questão de pesquisa}

Este estudo provém de dissertação de mestrado Aprender com Mobilidade: utilização das tecnologias da informação e comunicação móveis e sem fio como potencializadoras da interação em processos educativos, desenvolvida no âmbito do Programa de Pós-Graduação em Diversidade Cultural e Inclusão Social, da Universidade Feevale, Novo Hamburgo, RS. A dissertação foi desenvolvida na interseção dos projetos de pesquisa Ensinar e Aprender em/na Rede: a arquitetura de participação da web 2.0 no contexto da educação presencial ${ }^{1}$, que investiga o potencial da arquitetura da participação da web 2.0 no processo de ensino-aprendizagem presencial nos anos finais do ensino fundamental e o projeto Aprendizagem com Mobilidade: análise do impacto do uso das tecnologias móveis no processo de ensino e 
aprendizagem em crianças e adolescentes com necessidade de tratamento oncológico ${ }^{2}$, que foca na utilização das tecnologias móveis nos processos de ensino-aprendizagem de alunos em tratamento oncológico.

No Brasil, alunos ausentes da escola para tratamento de saúde são beneficiados pelo exercício domiciliar, atendimento especializado garantido por lei para alunos impossibilitados de frequentar a escola (BRASIL, 2005). A duração do período de ausência para tratamento de saúde pode se estender de 2 semanas até meses, período durante o qual os alunos ficam sem comparecer à aula, dependendo apenas de materiais que os pais ou responsáveis buscam na escola. Devido a problemas na operacionalização do exercício domiciliar, o aluno em tratamento de saúde, já fragilizado pela doença, sofre também por sentir-se excluído do contexto escolar, situação que resulta, muitas vezes, em reprovação, repetência e abandono da escola.

Em uma situação na qual alunos em tratamento de saúde encontram-se privados do contato com o contexto escolar, este estudo pretende possibilitar que tal contato possa ocorrer com a utilização das ferramentas da web 2.0, acessadas por meio das TIMS. Acredita-se que as possibilidades de interação e cooperação dessas ferramentas facilite o processo educativo, já que este pode ser acompanhado interativamente pelo aluno em exercício domiciliar, independente do local onde se encontre. Deste modo, o problema de pesquisa é investigar como o potencial de interação e cooperação das ferramentas da web 2.0, acessadas por meio de dispositivos do tipo TIMS, pode oportunizar a interação de alunos em exercício domiciliar com o contexto escolar.

As categorias de análise (LÜDKE e ANDRÉ, 1986) que orientam este estudo são provenientes do referencial teórico e refletem o propósito do estudo. Tais categorias são a escola e o exercício domiciliar (MEC, 2002), a escola e as tecnologias digitais (MACHADO, 2009), formação docente para utilização das tecnologias digitais (ZACARON et al, 2012), TIMS e a interação (PRIMO, 2000; SCHLEMMER et al., 2008), TIMS e a cooperação (PIAGET, 1973; HEPPEL, 2012; DRON \& ANDERSON, 2007; SILVA, 2002) e TIMS e aprendizagem móvel (SACCOL et al, 2011).

\section{Materiais, métodos e aplicação da proposta}

O objetivo geral do estudo consistiu em analisar como o potencial de cooperação das ferramentas da web 2.0, acessadas por meio de dispositivos móveis, pode oportunizar a interação de alunos em exercício domiciliar com o contexto escolar, representado por colegas, professores e conteúdos. Os objetivos específicos foram a) descrever a situação inicial do problema e o procedimento dispensado para o acompanhamento de estudos dos alunos em exercício domiciliar, b) selecionar ferramentas da web 2.0 com potencial de interação e cooperação, para aplicação da proposta, c) desenvolver proposta para promover interação e cooperação dos participantes da pesquisa com o contexto escolar (colegas, professores e conteúdo), com base nas ferramentas da web 2.0 acessadas por meio de dispositivos móveis (TIMS); d) validar a proposta formatada a partir da utilização com a turma regular e os alunos em exercício domiciliar; e) avaliar os resultados da prática à luz do referencial teórico.

A pesquisa, de abordagem qualitativa, aplicou como delineamento metodológico a categoria estudo de caso (YIN, 2010). Os instrumentos utilizados foram observação participante (ANGROSINO, 2009), diário de campo, entrevista e questionário (GIL, 2002; TOMAR, 2008). Além disso, utilizou-se uma proposta de prática, formulada pelo professor regente em parceria com o pesquisador. Tal proposta foi composta de atividades pedagógicas utilizando ferramentas da web 2.0, que alunos da classe regular acessaram utilizando computador do tipo desktop, no laboratório de informática escolar, e os alunos em exercício domiciliar acessaram utilizando TIMS do tipo tablets, de casa. 
A seleção dos sujeitos, pacientes oncológicos, observou os critérios de estar em tratamento de saúde (exercício domiciliar), ter idade mínima de 13 anos de idade, necessária para o acesso às ferramentas da web 2.0 selecionadas, e estar cursando os anos finais do Ensino Fundamental. As escolas frequentadas pelos alunos deveriam dispor de laboratório de informática com acesso à internet. No total, foram acompanhados 50 sujeitos. Foram dois alunos (14 e 15 anos), do gênero masculino, pacientes oncológicos em exercício domiciliar, estudantes em duas escolas públicas distintas. Também participaram a direção das escolas, os professores regentes das turmas e os colegas da classe regular (44 alunos, de ambos os gêneros, entre 14 e 16 anos).

Após entrevista inicial com a direção escolar, professores regentes das turmas e alunos em exercício domiciliar, o pesquisador e o professor regente elaboraram conjuntamente uma proposta de prática utilizando ferramentas web 2.0 acessadas por meio das TIMS. A proposta previu um período de realização de 4 semanas, com uma atividade de duas horas por semana, estando o professor no laboratório com a turma regular e o pesquisador acompanhando o aluno em exercício domiciliar.

A seleção de ferramentas da web 2.0 foi baseada na proposta de Hart (2013). A autora dirige o Centre for Learning \& Performance Technologies (C4LPT), que elabora e divulga anualmente uma listagem com as 100 ferramentas mais utilizadas no contexto educativo. Tomando como ponto de partida o relatório de Hart (2013) e o contexto educacional deste estudo, a seleção de ferramentas levou em conta três aspectos: a) aspectos tecnológicos; b) aspectos de compartilhamento e visibilidade; c) aspectos de acesso. A análise inicial considerou as 20 primeiras ferramentas do relatório de Hart (2013).

Com relação aos aspectos tecnológicos, priorizou-se ferramentas que atendessem aos critérios de acesso via TIMS, em função da especificidade da pesquisa em desenvolvimento. A redundância funcional eliminou da seleção ferramentas que cumprem a mesma função (por exemplo: a ferramenta Dropbox, para armazenamento de arquivos, apresenta redundância funcional com o Google Drive).

Nos aspectos de compartilhamento e visibilidade, foram priorizadas as ferramentas que atendessem aos 3 espaços que os sujeitos podem ocupar online (MeWe-See) ou ao menos aos espaços interativos coletivos We-See. Para Heppel (2012), o espaço $\mathrm{Me}(\mathrm{Eu})$ é o espaço privado, onde o sujeito tem liberdade de reflexão, registro de pensamentos e pode arriscar e tentar coisas novas. O segundo espaço é o We (Nós), no qual o sujeito pode compartilhar seu trabalho com amigos e pessoas que conheça e deseje compartilhar as informações. Este é o espaço de compartilhamento. Por fim, o espaço See (Ver) é o espaço público, onde todos os usuários da web podem ver as informações e outros materiais disponibilizados pelo autor.

As ferramentas foram ainda classificadas por critérios de compartilhamento (DRON \& ANDERSON, 2007), priorizando o uso coletivo/rede e favorecendo a interação e a cooperação.

Nos aspectos de acesso, as ferramentas foram separadas em síncronas ou assíncronas (SILVA, 2002). Essa diversificação permite que alunos e docentes possam estabelecer comunicação e interação em tempo real (síncrona) ou em momentos mais propícios a ambos, criando distintos espaços temporais de aprendizagem e oportunizando diferentes experiências de acesso e utilização.

Submetendo as ferramentas da web 2.0 (HART, 2013) aos critérios de seleção, foram selecionadas uma ferramenta de blog (Wordpress), uma rede social de vídeo (YouTube), uma ferramenta de chat (Facebook) e uma ferramenta de apresentação (Prezi). A proposta de prática, elaborada conjuntamente entre o pesquisador e o 
professor, envolveu atividades semanais com duas horas de duração. Objetivando estabelecer interação e cooperação entre os alunos em exercício domiciliar com o contexto escolar, as atividades articularam-se de forma a permitir utilização crescente dos recursos interativo-cooperativos das ferramentas.

A coleta dos dados envolveu, inicialmente, entrevistas com as direções das escolas, professores regentes e alunos em exercício domiciliar (agosto/2013). A proposta de prática foi aplicada em outubro e novembro de 2013. Após o desenvolvimento da prática, novamente foram realizadas entrevistas com os professores regentes, os alunos em exercício domiciliar e aplicou-se um questionário aos alunos da turma regular. As atividades foram realizadas em 4 semanas, com as atividades 1 e 2 (assíncronas) sendo acompanhadas pessoalmente pelo pesquisador na escola e junto ao aluno em exercício domiciliar, e as atividades 3 e 4 (síncronas) acompanhadas pelo professor, no laboratório, e pelo pesquisador, junto ao aluno em exercício domiciliar.

$\mathrm{Na}$ atividade 1, foi criado um blog e postado o assunto a ser discutido, utilizando para isso recursos de texto, imagens, animação e links. Os alunos, então, foram ao laboratório para acessar o conteúdo e apropriar-se dos conceitos. Da mesma forma, posteriormente, o aluno em exercício domiciliar executou o acesso. A atividade possibilitou, aos alunos, acessar o conteúdo da aula em forma de texto, imagens e recursos interativos. No final, todos os alunos, tanto da turma regular quanto o aluno em exercício domiciliar deixaram sua opinião sobre o conteúdo e a forma digital de exposição, expressando de forma escrita sua opinião.

A atividade 2 oportunizou aos alunos o aprofundamento do conteúdo postado no blog na semana anterior, utilizando agora recursos audiovisuais. O professor da escola A criou um vídeo autoral, e disponibilizou mais dois vídeos de repositórios do MEC, enquanto o professor B disponibilizou também aos alunos vídeos aprofundando o assunto estudado. Essa atividade articulou-se à anterior ao aprofundar os conteúdos tratados anteriormente, tanto por meio de vídeos postados pelo professor quanto pela inserção de novos tópicos e respostas aos comentários dos alunos executados na aula anterior. No final da atividade, os alunos responderam questionamentos, sendo estimulados a comentarem as postagens dos colegas. Estimulou-se a interação entre os alunos da classe e com o aluno em exercício domiciliar.

$\mathrm{Na}$ atividade 3, o chat, surgiu a abordagem do aspecto cultural das tecnologias digitais, expressa no fato de que esta é uma forma já estabelecida de troca de informações entre os alunos das turmas estudadas. A diferença é que, ao invés de assuntos do cotidiano dos alunos, o assunto do chat envolveu conteúdos didáticos. Por tratar-se de uma atividade síncrona, colegas da classe regular e aluno em exercício domiciliar interagiram simultaneamente. Os alunos da turma regular foram conduzidos pelo professor e o aluno em exercício domiciliar auxiliado pelo pesquisador.

Na atividade 4, o software de apresentação Prezi foi utilizado para que cada aluno, em dupla com um colega, mas em computadores fisicamente separados, construíssem conjuntamente uma apresentação sobre os conteúdos estudados e debatidos via blog, vídeo e chat. Através da ferramenta de apresentação os alunos puderam expressar sua compreensão do conteúdo. Esta atividade possibilitou a cooperação online, por meio da construção coletiva da apresentação. O aluno em exercício domiciliar, acompanhado pelo pesquisador, também trabalhou em dupla com um colega da classe regular, assistido pelo professor.

Após coleta dos dados, procedeu-se à análise e discussão dos resultados, à luz das categorias de análise, provenientes do referencial teórico e dos dados coletados. 


\section{Resultados e discussão}

Os dados resultantes do levantamento preliminar, da aplicação da proposta de prática de ensino e das entrevistas e questionários com os sujeitos são aqui analisadas, com vistas a responder ao objetivo geral do estudo: analisar como o potencial de cooperação das ferramentas da web 2.0, acessadas por meio de dispositivos móveis, pode oportunizar a interação de alunos em exercício domiciliar com o contexto escolar, representado por colegas, professores e conteúdos. As categorias, que emergiram do referencial teórico, são agora confrontadas com os dados obtidos.

$\mathrm{Na}$ análise da categoria escola e o exercício domiciliar, percebeu-se que, nas escolas estudadas, o exercício domiciliar não é operacionalizado conforme a legislação (BRASIL, 2005). Os alunos recebem esporadicamente algum material, de apenas alguns professores, e tal material não reflete a totalidade dos conteúdos, sendo considerado insuficiente para dar continuidade aos estudos. Não há um procedimento padrão estabelecido para o atendimento domiciliar nem para o reingresso desse aluno e não se utilizam as tecnologias digitais para alcançar este aluno fora do contexto escolar.

$\mathrm{Na}$ categoria a escola e as tecnologias digitais, com estudos que atestam a validade destas como recurso pedagógico (HOFFMANN, 2002; VALENTINI E SOARES, 2005; MACHADO, 2009; SACCOL ET AL, 2011), percebe-se um esforço do poder público em equipar as escolas com laboratórios de informática conectados à internet. Contudo, nas escolas estudadas existe apenas um laboratório de informática com 20 a 30 computadores, para atender toda a escola. Cada turma utiliza o computador apenas por um período de 2 horas semanais, para que todos possam fazer uso do espaço. Portanto, o número de laboratórios é insuficiente. A falta de um técnico, apontada pelas direções e professores, permite inferir que a manutenção dos laboratórios é deficiente.

Com relação à categoria formação docente, relatos de experiências positivas de atividades educacionais mediadas pelas tecnologias digitais demonstram que a inserção tecnológica, quando conjugada com professor preparado adequadamente para sua a utilização alteram substancialmente a efetividade do processo educacional. Entretanto, a utilização das tecnologias digitais como elemento estratégico na educação extrapola a aquisição do equipamento. O que foi possível constatar neste estudo é que os professores entrevistados não receberam orientação sobre a utilização pedagógica das tecnologias digitais em sua formação inicial. Tal fato é também reconhecido pelo poder público, que afirma haver "[..] fragilidade na capacitação dos professores, o que impacta diretamente a utilização dos laboratórios como suporte tecnológico ao processo de ensino-aprendizagem de matérias regulares, como matemática, história, ciências, geografia e língua portuguesa” (BRASIL, 2011, p. 38).

A categoria TIMS e interação analisou os dados à luz de que a aprendizagem não é um processo que decorre de estruturas internas do indivíduo, mas da interação com o objeto do conhecimento (PIAGET, 1973). As redes eletrônicas propiciam a construção do conhecimento pelo sujeito por meio da interação, facilitada pelas ferramentas da web 2.0 acessadas através dos dispositivos móveis e sem fio do tipo TIMS (SCHLEMMER et. al, 2007; SACCOL et al., 2011). Foi possível perceber que, ao permitir que o aluno em exercício domiciliar pudesse acessar o conteúdo de sua casa ou do hospital, as TIMS representaram uma oportunidade de compartilhar de um contexto de aprendizagem que compensou a ausência na classe regular. Ao mesmo tempo, verificou-se que, além de ter beneficiado o aluno em exercício domiciliar, as TIMS tornaram o aprendizado uma experiência interessante e atrativa para os alunos, conectando interativamente todos os envolvidos no processo.

Com relação à categoria TIMS e a cooperação, durante a utilização da ferramenta Prezi, foi possível detectar vários momentos de atividades cooperativas, 
necessárias para a execução das tarefas, já que a tarefa envolveu dois alunos fisicamente distantes. Percebeu-se uma gradação dos estímulos interativo-cooperativos da primeira à última atividade. Na Atividade $1, \operatorname{blog}$, apenas se pedia que o aluno acessasse o conteúdo e desse uma opinião. Já na Atividade 2, além da inclusão de mais conteúdos e vídeos, era necessário responder questões. Na atividade 3 , as questões deviam ser respondidas em conjunto via chat e na Atividade 4, uma apresentação devia ser construída coletivamente. Assim, a cooperação se tornou mais e mais intensa, na troca de informações sobre o problema a ser resolvido. Por meio das atividades, foi possível perceber que as trocas foram mais do que uma contribuição individual, envolveram uma operação de cooperação (atuação em conjunto), visando resolver a tarefa proposta. Ao utilizar as ferramentas da web 2.0, conectadas pelas TIMS, a presencialidade foi substituída pelo diálogo cooperativo, que permitiu construir conceitos e chegar a um resultado.

Com relação à visibilidade (HEPPEL, 2012), as ferramentas blog e vídeo estimularam a interação e a colaboração entre os colegas do grupo (We). Ao mesmo tempo, com o resultado dessa interação disponibilizado publicamente na web, o espaço See surge, já que qualquer interessado pode acessá-las. A criação da apresentação coletiva permitiu ao aluno em exercício domiciliar interagir em atividades síncronas.

O blog abriu possibilidade para que a construção do conhecimento ocorresse coletivamente, com o estímulo para a discussão surgindo a partir da ferramenta (DRON \& ANDERSON, 2007). No caso do chat, quando surge o questionamento do professor sobre membrana plasmática e transporte celular ("Por que uma pessoa que tem uma dieta rica em proteínas deve ingerir uma quantidade grande de água ?”), os alunos construíram coletivamente uma definição mais completa do que quando o fizeram individualmente (figura 1).

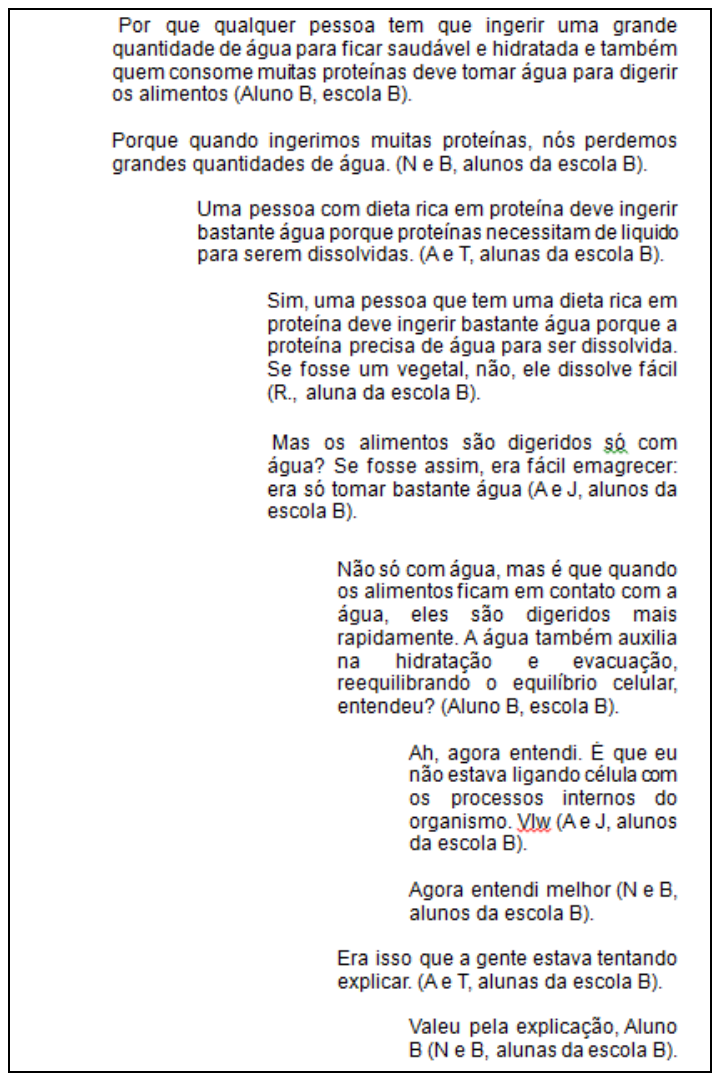

Figura 1. Chat sobre o membrana plasmática e transporte celular 
O Prezi foi outro exemplo de emergência do coletivo. No momento em que os alunos resolveram tornar público e reutilizável sua apresentação na rede social Facebook, eles tornaram-na disponível para ferramentas de busca na web e disponível para qualquer internauta (DRON \& ANDERSON, 2007). A análise permite constatar, portanto, que a interação mútua e a cooperação foram estimuladas por meio do formato da postagem feita pelos professores somado às potencialidades das ferramentas da web 2.0. Ao apresentarem a possibilidade de utilização móvel, as ferramentas permitiram que os alunos não só se mantivessem em contato com o contexto escolar, mas também que os mesmos cooperassem virtualmente, permitindo a construção do conhecimento.

Relacionado à categoria TIMS e a Aprendizagem Móvel, percebeu-se que, ao permitir o acesso através de dispositivos móveis do tipo TIMS as ferramentas da web 2.0 possibilitaram a operacionalização da aprendizagem móvel. Neste estudo, o tablet permitiu aos alunos em exercício domiciliar acessar o contexto escolar. Esse acesso, que permitiu interação e cooperação com os conteúdos, colegas e os professores, só foi possível graças às TIMS, pois os alunos $\mathrm{A}$ e $\mathrm{B}$ estavam em exercício domiciliar, sem condições de deslocar-se até a escola. Ao utilizar tais recursos, o professor regente não só disponibilizou conteúdo, mas 0 fez em ferramentas que propiciaram o desenvolvimento de processos interativo-cooperativos que permitiram a construção do conhecimento (PIAGET, 1973; PRIMO, 2000).

O atual cenário de padrão crescente de conexão à web possibilita a emergência de novos padrões sociais, entre eles a aprendizagem móvel ou mobile learning (SACCOL et al, 2011). A totalidade dos professores possuíam dispositivos do tipo TIMS, os alunos A e B responderam que seus smartphones acessavam a internet e $65 \%$ dos colegas da turma regular possuem smartphone com possibilidades de acesso à rede. As TIMS conectadas às ferramentas da web 2.0 possibilitaram aos alunos em exercício domiciliar o acesso ao conteúdo em condições similares a de seus pares no laboratório de informática da escola, permitindo a aprendizagem móvel.

\section{Considerações finais}

$\mathrm{Na}$ implementação de qualquer plano de ação ou projeto que leve em consideração a utilização pedagógica das tecnologias digitais, é fundamental a seleção criteriosa de recursos capazes de propiciar condições pedagógicas estimulantes para a interação e a cooperação, base para a construção do conhecimento. Com base na epistemologia interacionista-construcionista, infere-se que a troca de experiências interativas proporcionada pelas tecnologias digitais faz emergir condições propícias para que a aprendizagem aconteça. Neste estudo, a interação e a cooperação, estimuladas pelas ferramentas sociais da web 2.0, proporcionaram a troca de experiências e opiniões, e a construção de conceitos, favorecendo a aprendizagem.

O estudo levantou questões consideradas fundamentais no âmbito deste estudo, como o fato de que o exercício domiciliar, tal qual é operacionalizado pelas escolas estudadas, não possibilita ao aluno acompanhar o andamento dos conteúdos na sua totalidade, pois o simples envio de cópias e exercícios não contempla todos os conteúdos transmitidos em sala de aula e, portanto, não possibilita que o mesmo construa seu conhecimento. Constatou-se que os laboratórios de informática das escolas são insuficientes para atender o total de alunos, faltando também suporte técnico para manter o equipamento em níveis que permitam sua utilização. Verificou-se que os docentes não têm formação percebida como suficiente para que possam fazer uso pedagógico das tecnologias digitais.

As tecnologias foram colocadas nas escolas, mas o suporte técnico e o currículo de preparação e atualização docente para utilização tecnológica digital na mediação dos 
processos educativos não foi contemplado na mesma amplitude. Não é a tecnologia isolada que modificará a ação escolar, mas aquilo que o docente é capaz de fazer com a tecnologia é que determinará seu sucesso. É dever das políticas públicas inserir instrumentos que deem conta de uma informatização abrangente, providenciando suporte técnico aos laboratórios e capacitação docente inicial e continuada.

O potencial interativo-cooperativo das ferramentas da web 2.0 utilizadas neste estudo foi atingido. O conteúdo, questionamentos e atividades propostas no blog permitiram interação mútua, enquanto o vídeo possibilitou a construção de conceitos através de recursos audiovisuais. Ao permitir maior criatividade e rapidez no contato, as ferramentas chat e Prezi possibilitaram cooperação e construção mútua de conceitos.

Com relação aos aspectos sociais da interação e cooperação, constatou-se que os alunos trabalharam nos níveis de grupo, rede e coletivo. Observou-se a construção de conhecimento interativo-cooperativo quando os questionamentos postados pelo professor estimularam os alunos a participar. A construção de conceitos por meio das discussões envolvendo os alunos do laboratório e os alunos em exercício domiciliar confirmam a validade da utilização pedagógica das tecnologias digitais.

Considera-se que a utilização das TIMs possa contribuir para que os processos educativos, cada vez mais, possam ocorrer com qualidade, independente do local onde os alunos estejam. A utilização das TIMS conectadas às ferramentas da web 2.0, para o contexto escolar, significa potencial avanço às possibilidade de interação e cooperação que possibilita a aprendizagem móvel.

Este estudo apresentou resultados em níveis indicativos e, portanto, sugere-se a ampliação do mesmo, a fim de cobrir um espectro mais amplo da situação educacional, validando os dados aqui apresentados de uma maneira representativa.

Visando estender este estudo, apresenta-se como proposta de estudos futuros a ubiquidade. O advento e crescimento da computação ubíqua se apresenta como promessa concreta de avanço do conceito de aprendizagem móvel, através da naturalização da utilização tecnológica digital, integrando os recursos digitais às ações e comportamentos naturais das pessoas. Ao apresentar a informação relevante para o contexto onde a pessoa está, a computação ubíqua se coloca como a última fronteira dos processos educativos, permitindo aprender em todos os momentos, de todas as maneiras, em todos os lugares.

As ferramentas da web 2.0, acessadas por meio das TIMS, centram o aprendizado na experiência do aluno e reafirmam seu papel de protagonista no processo de construção de seu conhecimento, com a mediação do professor. Assim, a aprendizagem móvel apresenta-se como uma possibilidade real de utilização das TIMS para promover processos educacionais mais abrangentes e inclusivos.

\section{Notas de texto}

${ }^{1}$ Projeto contemplado no edital MCTI /CNPq /MEC/CAPES n ${ }^{\circ}$ 18/2012, coordenado pela Prof. ${ }^{\text {a }}$ Dr ${ }^{\mathrm{a}}$. Patrícia Brandalise Scherer Bassani, da Universidade Feevale

2 Projeto contemplado no edital MCTI/CNPq/MEC/CAPES $N^{\circ}$ 07/2011, coordenado pela Prof. ${ }^{\text {. }}$ Dra . Débora Nice Ferrari Barbosa.

3 Considera-se que possibilidade de acesso não significa, necessariamente, acesso efetivo, pois condições socioeconômicas podem permitir a aquisição do aparelho, mas não o pagamento da mensalidade da assinatura de acesso à internet (autores).

\section{Referências}

ANGROSINO, M. Etnografia e observação participante. Trad. José Fonseca. Porto Alegre: Artmed, 2009. 
BRASIL Decreto no $\mathbf{5 . 6 2 2}$ de 19 de dezembro de 2005. Brasília, DF: Presidência da República, 2005.

BRASIL. Controladoria Geral da União. Relatório de avaliação da execução de programas de governo $n^{\circ} 16$ - Infraestrutura de Tecnologia da Informação para a educação básica pública (PROINFO). Brasília, DF, 2011.

DRON, J.; ANDERSON, T. Collectives, Networks, Groups in Social Software for eLearning. Cheasapeake, USA, 2007.

HART, J. Top 100 Tools for Learning. Disponível em

<http://c4lpt.co.uk/top100tools/> Acesso: mar 2013.

HEPPEL, S. Online Spaces (2012) Disponível em

<http://www.education.vic.gov.au/management/lol/lead.spaces.htm> Acesso: mai 2013.

LEMOS, A. Cibercultura. Porto Alegre: Sulina, 2010.

LÜDKE, M., ANDRÉ, M.E. A. Pesquisa em educação: Abordagens qualitativas. São Paulo, EPU, 1986.

MACHADO, Ana Claudia Teixeira. Novas Formas de Produção de Conhecimento: utilização de ferramentas da WEB 2.0 como recurso pedagógico Revista Udesc Virtu@l (2009). Disponível em

http://periodicos.udesc.br/index.php/udescvirtual/article/viewFile/1655/1332> Acesso em 26 dez 2012.

MEC. Ministério da Educação. Exercício domiciliar Disponível em $<$ http://portal.mec.gov.br/cne/arquivos/pdf/CEB031_2002.pdf> Acesso em: jan 2012.

O'REILLY, T. What is web 2.0: design patterns and business models for the next generation of software. Disponível em: http://oreilly.com/pub/a/web2/archive/what-isweb-20.html. Acesso: nov. 2007.

PIAGET, J.A epistemologia genética. 2a ed. Petrópolis (RJ): Vozes; 1973.

PRIMO, A. Interação mútua e reativa. Rev. Famecos, n. 12, jun. 2000.

PRIMO, A.; SMANIOTTO, A. M. R. Blogs como espaços de conversação: interações conversacionais na comunidade de blogs insanus. E-Compós, v. 1, n. 5, p. 1-21, 2006. SACCOL, A.; SCHLEMMER, E.; BARBOSA, J. M-learning e u-learning: novas perspectivas das aprendizagens móvel e ubíqua. São Paulo: Prentice Hall, 2011. SCHLEMMER, E.; SACCOL, A.; BARBOSA, J.; REINHARD, N. M-learning ou aprendizagem com mobilidade. In: $13^{\circ}$ Congresso Internacional ABED de EaD. Curitiba: 2007.

SILVA, V. Ferramentas de comunicação síncronas e assíncronas. 2002. Disponível EM <http://br.geocities.com/portaltoolbox/CALL_ferramentaSinAss.html> Acesso: jun 2012.

TOMAR, M. S.: A entrevista semiestruturada. 2008. Disponível em $<$ mariosantos700904.blogspot.com/2008/05/matriz-do-guio-de-uma-entrevistasemi.html> Acesso: ago. 2012.

VALENTINI, C. B., SOARES, E. M. S. (orgs.). Aprendizagem em Ambientes Virtuais: compartilhando ideias e construindo cenários. Caxias do Sul: EDUCS, 2005. YIN, R. Estudo de caso: planejamento e métodos. Porto Alegre: Bookman, 2010. ZACCARON, A. B. M., SOUZA, M. R. S.; AMARO, L. S. M.; SERRES, F. F.; NEVADO, R. A. Uso Pedagógico das Tecnologias Digitais. RENOTE, v. 10, n. 3, 2012. 